\title{
BMJ Open Mediating effect of coping style on the relationship between clinical leadership and quality of work life among nurses in tertiary-level hospitals in China: a cross-sectional study
}

Hongli Li, ${ }^{1}$ Hui Chang, ${ }^{2}$ Zijun Tao, ${ }^{1}$ Dan Zhang, ${ }^{1}$ Ying Shi, ${ }^{1}$ Xiaofei Li (D) ${ }^{3}$

To cite: Li H, Chang H, Tao Z, et al. Mediating effect of coping style on the relationship between clinical leadership and quality of work life among nurses in tertiary-level hospitals in China: a crosssectional study. BMJ Open 2021;11:e041862. doi:10.1136/ bmjopen-2020-041862

- Prepublication history for this paper is available online. To view these files, please visit the journal online (http://dx.doi. org/10.1136/bmjopen-2020041862).

Received 30 June 2020 Revised 22 January 2021 Accepted 02 February 2021

D) Check for updates

(c) Author(s) (or their employer(s)) 2021. Re-use permitted under CC BY-NC. No commercial re-use. See rights and permissions. Published by BMJ.

${ }^{1}$ School of Nursing, China Medical University, Shenyang, China

${ }^{2}$ Department of Health

Promotion, Center for Health Services of Liaoning Province, Shenyang, China

${ }^{3}$ Department of Transplantation and Hepatobiliary, China

Medical University First Hospital, Shenyang, China

Correspondence to

MSN Xiaofei Li;

lixiaofei0603@aliyun.com

\section{ABSTRACT}

Objective To explore the association between clinical leadership and quality of work life, as well as the mediating role of coping style in this relationship.

Setting Three tertiary-level hospitals in Liaoning Province, China.

Participants A total of 1209 nurses were recruited for this study. Registered nurses who work full time with at least 1 year of work experience were eligible as subjects. Exclusion criteria were nurses who work indirectly with patients, such as in education, administration or research. Primary and secondary outcome

measures Questionnaires consisting of the work-related Quality of Life Scale, the Nurse Leadership Scale and the Simplified Coping Style Questionnaire, as well as a demographic data sheet, were used to collect participant information. Pearson's correlation analysis, hierarchical multiple regression analysis, and asymptotic and resampling strategies were used to analyse the data. Results The mean overall quality of work life score among Chinese nurses was $3.50 \pm 0.60$. After adjusting for demographic characteristics, clinical leadership was positively associated with the score of quality of work life ( $\beta=0.55, p<0.01$ ). Clinical leadership explained $27 \%$ of the variance in quality of work life. Coping style partially mediated the relationship between clinical leadership and quality of work life. The proportion of mediation of active coping was $21.82 \%$ and of passive coping was $5.79 \%$. Conclusions Clinical leadership was positively associated with quality of work life and coping style partially mediated the relationship between clinical leadership and quality of work life among nurses in China. Implementing measures focusing on both clinical leadership and coping style may provide success in improving the quality of work life of nurses.

\section{INTRODUCTION}

Quality of work life (QWL) is defined as an approach which focuses on the individual, rather than organisational, goals and is aimed at improving the outcomes of both the individual and the organisation. ${ }^{1}$ QWL has been described as being one of the most important
Strengths and limitations of this study

- This is one of the first studies that focuses on the clinical leadership of nurses and explores its relationship with quality of work life among nurses in China.

- A variety of statistical methods (descriptive analysis, Pearson's correlation analysis and hierarchical multiple regression analysis) were employed to investigate the relationship between independent variables and quality of work life. Asymptotic and resampling strategies were used to explore the mediating role of coping style.

- Clinical leadership was obtained from self-reports and this self-report bias might have affected the results.

factors to attract and retain talented employees and to ensure a high quality of performance. ${ }^{23}$ As the largest group of healthcare professionals, nurses play a primary role in healthcare outcomes. ${ }^{45}$ Nurses provide care to patients with various and changing needs using their knowledge, skills, and experience to meet the demands of patient care and work toward the desired health outcomes. It has been previously reported that the nursing workforce plays a significant role in optimising health outcomes, such as the improvement in people's health status as well as in morbidity and mortality reduction. ${ }^{6-8}$ However, nurses are challenged by work pressure, exposure to risks, moral and ethical distresses, and the high demands of patients and their loved ones, all of which threaten their well-being, work effectiveness and influence job turnover. $^{9-11}$ Nurses also must engage in additional responsibilities such as professional and continuing education and workplace management. Therefore, some nurses struggle in creating and maintaining 
a balanced personal and professional life. ${ }^{12}$ These factors may directly or indirectly affect the overall health status and well-being of nurses, thereby impacting the quality of services they provide to patients. As a result, the QWL among nurses has declined. Previous studies have shown that improving QWL of nurses helps to ensure organisational stability and reduce turnover rates. ${ }^{13-15}$ Therefore, improving QWL of nurses is an urgent, although challenging, problem for medical administrators. ${ }^{16}$

Leadership is defined as someone (ie, the leader) persuading at least one other person (ie, the follower) to work jointly to accomplish a common goal. ${ }^{17}$ Clinical leadership has recently been identified as one of the most important competencies a nurse can present. ${ }^{18}$ In clinical practice, nurses are usually challenged with multitasks, including implementation of medical orders, patientorientated health education and so on. Therefore, in the process of patient caring, nurses are perceived as clinical leaders, who are responsible for efficient and high-quality patient management and communication, thus ensuring the best health outcomes for patients. ${ }^{19}$ Previous studies have demonstrated that clinical leadership is associated with patient safety, quality of healthcare and the career development of nurses. ${ }^{20}$ Using the phenomenographical approach, Rosengren et $a l^{21}$ showed that clinical leadership of nurses was considered to be defined as 'being present and available in daily work', 'supporting everyday practice', 'facilitating professional acknowledgement', and 'improving care both as individuals and as a team'. Munir et $a t^{22}$ also demonstrated that leadership style is directly associated with perceptions of work-life conflict, improvement of work-life balance and employee wellbeing among healthcare employees.

Coping style is an important psychological resource for an individual to deal with stress. ${ }^{23}$ It plays a key role in stressors and stress reactions during stressful encounters. ${ }^{24}$ Active coping styles can enhance positive emotions, improve job satisfaction and increase employee retention rate. ${ }^{25}$ Contrarily, individuals who use more passive coping styles tend to doubt their abilities and have worse mental health, therefore lowering their quality of life. ${ }^{27}$ According to the transactional model of stress and coping proposed by Lazarus and Folkman in $1984,{ }^{28}$ an individual's reaction to a stressful event is mediated by their subjective evaluation (ie, appraisal) of the environment and their process of coping with the event. Appraisals of situations and coping behaviour are influenced by characteristics such as personality, competence and social skills. Clinical leadership is considered a professional competency for nurses, as it is a 'complex know-act' that nurses develop for the quality of care for patients and their families. ${ }^{29}$ However, to our knowledge, the relationship between clinical leadership and coping style among Chinese nurses has not been examined.

There are numerous studies focusing on the leadership of nurse managers in a variety of different sectors and countries. ${ }^{30-33}$ However, little is known about the clinical leadership of nurses and the associations between clinical

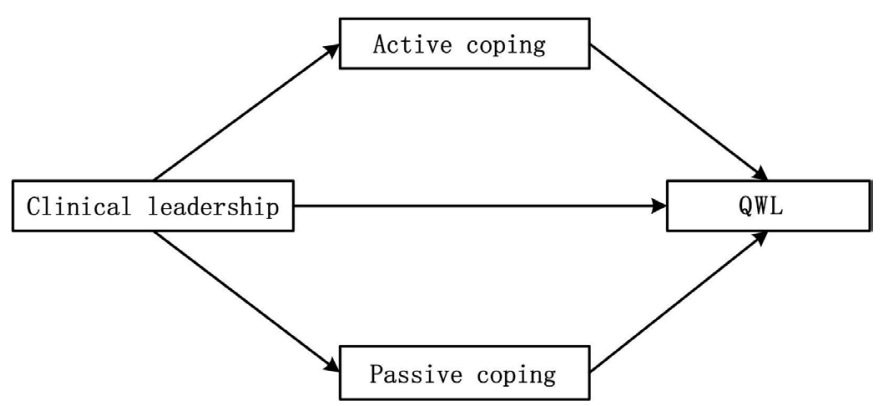

Figure 1 Hypothetical mediation model of coping style mediated the relationships between clinical leadership and QWL. QWL, quality of work life.

leadership and QWL among nurses in China. In addition, few have attempted to address the modulating effect of coping style on clinical leadership and QWL for Chinese nurses. Based on Lazarus and Folkman's transitional model and empirical evidence, this study's conceptual framework is presented in figure 1. We hypothesised that (H1) clinical leadership positively and directly influences QWL; (H2) clinical leadership indirectly influences QWL through active coping or passive coping style; (H3.1) active coping style positively and directly influences QWL; and (H3.2) passive coping style negatively and directly influences QWL.

\section{METHODS \\ Design and sampling}

From May 2019 to August 2019, the current study was conducted using a descriptive cross-sectional survey design. There are 90 tertiary hospitals in Liaoning Province. They are divided into three groups: the universityaffiliated hospitals, provincial tertiary hospitals and municipal tertiary hospitals. One hospital was randomly selected from each group and three hospitals were selected. Registered nurses who worked full time with at least 1 year of work experience were eligible as subjects. Exclusion criteria were nurses who worked indirectly with patients, such as in education, administration or research. We obtained permission from the managers and human resources departments of the hospitals. The paper questionnaire was distributed by the research team members during the morning shift and explained the aims and procedures of the study for the participants. The questionnaire was collected anonymously to ensure confidentiality. The completed questionnaires were put into an opaque box in the nurse station and were retrieved by the research team members 1 week after they were distributed. Collected data were kept confidential and used only for this study. A total of 1742 questionnaires were delivered to nurses and 1265 questionnaires were ultimately collected. The response rate for each hospital was $66.9 \%, 70.1 \%$ and $77.9 \%$, respectively. Fifty-six questionnaires were excluded from the analysis due to missing data (of more than 30\%). A total of 1209 questionnaires 
from nurses were included in the analysis, with an overall valid response rate of $69.4 \%$.

\section{Questionnaires}

\section{Demographic data}

Demographic data include gender, age, work experience, marital status, work unit, work rank, educational level, pregnancy, breast feeding, number of children, looking after the elderly, night shift (per week), frequent overtime work, sleep disorders and diagnosis of chronic diseases. Age was categorised as $\leq 25,26-30,31-35,36-40$, and $\geq$ 41years. Years of work experience was categorised as $\leq 5$, $6-10,11-15$ and $\geq 16$ years, and marital status was categorised as single, married and divorced/separated/widow. Work unit was categorised as internal medicine, general surgery, gynaecology/paediatrics and others, and work rank was categorised as junior, intermediate and senior. Educational level was categorised as less than a bachelor's degree and bachelor's degree or higher. Pregnancy as well as breast feeding was categorised as a yes or no. Number of children was categorised as 0,1 and $\geq 2$, and looking after the elderly was defined as yes if they needed to take care of elderly family members. Night shift (per week) was categorised as $0,1,2$ and $\geq 3$, and frequent overtime work was defined as yes if the frequency of required overtime work for the nurse was twice a week or more and work overtime was more than 1 hour each time. The presence of a sleep disorder was categorised as a yes or no, and the presence of a chronic disease was defined as yes if any of the predefined chronic diseases (hypertension, cardiovascular disease, diabetes, chronic kidney disease, back pain or ulcer) had ever been diagnosed.

\section{Work-related Quality of Life Scale-2}

The QWL was assessed with the Chinese version of the work-related Quality of Life Scale-2 (WRQoL-2). ${ }^{34}$ The WRQoL-2 consists of seven subscales of job and career satisfaction, general well-being, home-work interface, stress at work, control at work, working conditions and employee engagement. Participants responded to items on a Likert scale from 1 (strongly disagree) to 5 (strongly agree). Negatively worded items for the stress at work subscale were reversely scored prior to the analysis. Higher scores indicate a higher quality of nursing work life. In the current study, the Cronbach's alpha was 0.96 for the scale and ranged from 0.72 to 0.90 for each of the subscales.

\section{Nurse Leadership Scale}

Clinical leadership was measured by the Chinese version of the Nurse Leadership Scale (NLS), developed by Jia. ${ }^{35}$ The NLS is a 46-item scale consisting of seven subscales, including interpersonal skills, communication skills, problem-solving, critical thinking, organisation and planning, nursing professional competence and selfcare. Responses are scored on a 5-point Likert scale, with $1=$ strongly disagree and $5=$ strongly agree. The NLS has been validated by many studies, reflecting a high internal consistency within test items. ${ }^{35} 36$ In the current study, the Cronbach's alpha was 0.98 for the scale and ranged from 0.88 to 0.94 for each of the subscales.

\section{Simplified Coping Style Questionnaire}

Coping style was measured by the Simplified Coping Style Questionnaire (SCSQ). The SCSQ was developed by Xie, ${ }^{37}$ based on a broad Coping Style Questionnaire and revised in accordance with Chinese context. The questionnaire consists of 20 items that include two dimensions: active coping and passive coping. The items were measured using a 4-point Likert scale ( $0=$ never; $3=$ very often $)$. The Cronbach's alpha was 0.73 for the current study and ranged from 0.64 to 0.87 for each of the subscales.

\section{Statistical analysis}

All analyses were conducted using SPSS V.20.0 for Windows and all statistical tests were two-sided $(\alpha=0.05)$. The distribution of the QWL among categorical demographic characteristics was tested using a one-way analysis of variance. Correlations among QWL, clinical leadership and coping style were preliminarily examined using a Pearson's correlation analysis.

A hierarchical multiple regression analysis was performed to test the effects of groups of independent variables on QWL. QWL was used as the dependent variable. The analysis was performed in stages by successively inputting three blocks of independent variables into the model. Control variables were entered in block 1 . Because work unit and work rank were categorical variables without a linear trend, dummy variables were independently set for these two variables. In block 2, clinical leadership was added and in block 3 coping styles were added.

Asymptotic and resampling strategies were used to examine coping style as a mediating factor on the association between clinical leadership and QWL ${ }^{38}$ The total effect (path c), the direct effect (path c') and the indirect effects (path $\mathrm{a} \times \mathrm{b})$ are presented. The bias-corrected and accelerated (BCa) 95\% CIs for each axb product was calculated, where a BCa 95\% CI excluding 0 indicated a significant mediation. In the current study, 5000 bootstrap samples were used. Selection of control variables was based on the statistical significance of the univariate analysis. Clinical leadership was modelled as the independent variable, with QWL as the dependent variable, and coping styles (active and passive coping) as the mediators.

\section{Patient and public involvement \\ No patient involved.}

\section{RESULTS}

Demographic characteristics and the mean score of WRQoL-2 A total of 1209 nurses participated in the survey and the mean age was 31.85 ( $\mathrm{SD}=7.14$, ranging from 21 to 55 years). Demographic characteristics and other participant information, as well as the results of the univariate 


\begin{tabular}{|c|c|c|c|c|c|c|c|c|c|}
\hline \multicolumn{5}{|c|}{ Table 1 Demographic characteristics of participants and } & \multicolumn{5}{|c|}{ Table 1 Continued } \\
\hline \multirow{3}{*}{ Variable } & \multirow{3}{*}{ n (\%) } & $(n=1209)$ & 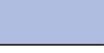 & \multirow{3}{*}{$\begin{array}{l}P \\
\text { value }\end{array}$} & \multirow{3}{*}{$\begin{array}{c}\text { Variable } \\
\text { No }\end{array}$} & \multirow{2}{*}{ n (\%) } & \multirow{2}{*}{$\begin{array}{l}\text { WRQoL-2 } \\
\text { mean (SD) }\end{array}$} & \multirow{3}{*}{$\mathbf{t} / \mathbf{F}$} & \multirow{2}{*}{$\begin{array}{l}\mathbf{P} \\
\text { value }\end{array}$} \\
\hline & & \multirow{2}{*}{$\begin{array}{l}\text { WRQoL-2 } \\
\text { mean (SD) }\end{array}$} & \multirow{2}{*}{$\mathbf{t} / \mathbf{F}$} & & & & & & \\
\hline & & & & & & 1151 (95.2) & $3.49(0.60)$ & & \\
\hline Gender & & & 0.95 & 0.135 & Yes & $58(4.8)$ & $3.53(0.55)$ & & \\
\hline Female & $1172(96.9)$ & $3.49(0.60)$ & & & Breast feeding & & & -0.29 & 0.771 \\
\hline Male & $37(3.1)$ & $3.59(0.74)$ & & & No & $1100(91.0)$ & $3.49(0.60)$ & & \\
\hline Age & & & 0.95 & 0.435 & Yes & $109(9.0)$ & $3.51(0.58)$ & & \\
\hline$\leq 25$ & $190(15.7)$ & $3.52(0.60)$ & & & Number of & & & 0.36 & 0.697 \\
\hline $26-30$ & $459(38.0)$ & $3.49(0.62)$ & & & children & & & & \\
\hline $31-35$ & 321 (26.6) & $3.45(0.58)$ & & & 0 & $566(46.8)$ & $3.51(0.61)$ & & \\
\hline $36-40$ & $86(7.1)$ & $3.56(0.65)$ & & & 1 & $589(48.7)$ & 3.49 (0.59) & & \\
\hline$\geq 41$ & $153(12.7)$ & $3.53(0.57)$ & & & $\geq 2$ & $54(4.5)$ & $3.44(0.61)$ & & \\
\hline Year(s) working & & & 1.63 & 0.180 & Looking after the & & & 3.58 & $<0.001$ \\
\hline$\leq 5$ & 397 (32.8) & $3.53(0.61)$ & & & elderly & & & & \\
\hline $6-10$ & $433(35.8)$ & $3.45(0.59)$ & & & No & $620(51.3)$ & $3.56(0.58)$ & & \\
\hline $11-15$ & $154(12.7)$ & $3.48(0.63)$ & & & Yes & $589(48.7)$ & $3.43(0.61)$ & & \\
\hline$\geq 16$ & 225 (18.6) & $3.53(0.59)$ & & & Sleep disorders & & & 11.19 & $<0.001$ \\
\hline Marital status & & & 0.09 & 0.916 & No & $560(46.3)$ & $3.69(0.55)$ & & \\
\hline Single & $363(30.0)$ & $3.51(0.60)$ & & & Yes & $649(53.7)$ & $3.32(0.59)$ & & \\
\hline Married & $818(67.7)$ & $3.49(0.60)$ & & & Chronic disease & & & 7.48 & $<0.001$ \\
\hline Divorced/ & $28(2.3)$ & $3.52(0.48)$ & & & No & 947 (78.3) & $3.56(0.57)$ & & \\
\hline $\begin{array}{l}\text { separated/ } \\
\text { widowed }\end{array}$ & & & & & Yes & $262(21.7)$ & $3.26(0.64)$ & & \\
\hline Work unit & & & 3.89 & 0.009 & $\begin{array}{l}\text { Frequent } \\
\text { overtime work }\end{array}$ & & & 8.19 & $<0.001$ \\
\hline Internal & $384(31.8)$ & $3.54(0.62)$ & & & No & 919 (76.0) & $3.57(0.58)$ & & \\
\hline medicine & 56 & 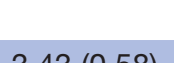 & & & Yes & $290(24.0)$ & $3.25(0.61)$ & & \\
\hline
\end{tabular}

$\begin{array}{lll}\begin{array}{l}\text { General } \\ \text { surgical }\end{array} \quad 530(43.8) & 3.43(0.58)\end{array}$

$\begin{array}{lcccc}\begin{array}{l}\text { Gynaecology/ } \\ \text { paediatrics }\end{array} & 75(6.2) & 3.57(0.53) & & \\ \text { Others } & 220(18.2) & 3.56(0.63) & & \\ \text { Work rank } & & & 11.29 & <0.001 \\ \quad \text { Junior } & 196(16.2) & 3.68(0.61) & & \\ \text { Intermediate } & 696(57.6) & 3.45(0.59) & & \\ \quad \text { Senior } & 317(26.2) & 3.48(0.61) & & \\ \text { Educational level } & & & 0.70 & 0.484\end{array}$

\begin{tabular}{lllll}
$\begin{array}{l}\text { Lower than } \\
\text { bachelor's } \\
\text { degree }\end{array}$ & $256(21.2)$ & $3.52(0.63)$ & & \\
$\begin{array}{l}\text { Bachelor's } \\
\text { degree or } \\
\text { higher }\end{array}$ & $953(78.8)$ & $3.49(0.53)$ & & \\
$\begin{array}{l}\text { Nightshift (per } \\
\text { week) }\end{array}$ & & & 7.57 & $<0.001$ \\
\hline No & $334(27.6)$ & $3.58(0.58)$ & & \\
1 & $192(15.9)$ & $3.59(0.60)$ & & \\
2 & $379(31.3)$ & $3.46(0.59)$ & & \\
\hline 3 & $304(25.1)$ & $3.39(0.62)$ & & \\
\hline Pregnant & & & -0.38 & 0.704 \\
\hline & & & & Continued \\
\hline
\end{tabular}

WRQoL-2, work-related Quality of Life Scale-2.

analysis, are presented in table 1 . Results of the univariate analysis demonstrated that work unit, work rank, night shift, looking after elderly people, sleep disorders, chronic diseases and frequent overtime work were significantly associated with QWL $(\mathrm{p}<0.01)$ and these variables were, therefore, entered as control variables in the hierarchical multiple linear regression analysis.

Correlations among QWL, clinical leadership and coping style As shown in table 2, both clinical leadership and coping styles were both significantly related to QWL. Clinical

Table 2 Means, SDs and correlations of all variables

\begin{tabular}{llllll}
\hline Variables & Mean & SD & $\mathbf{1}$ & $\mathbf{2}$ & $\mathbf{3}$ \\
\hline 1 WRQoL-2 & 3.50 & 0.60 & & & \\
2 NLS & 3.82 & 0.60 & $0.58^{\star}$ & & \\
3 Active coping & 1.99 & 0.49 & $0.50^{\star}$ & $0.58^{*}$ & \\
4 Passive coping & 1.08 & 0.44 & $-0.32^{*}$ & $-0.28^{\star}$ & $-0.14^{\star}$ \\
\hline
\end{tabular}

${ }^{*} \mathrm{P}<0.01$ (two-tailed).

NLS, Nurse Leadership Scale; WRQoL-2, work-related Quality of Life Scale-2. 
Table 3 Hierarchical multiple linear regression analysis results

\begin{tabular}{|c|c|c|c|}
\hline \multirow[b]{2}{*}{ Variables } & \multicolumn{3}{|l|}{ WRQOL-2 } \\
\hline & Step $1(\beta)$ & Step $2(\beta)$ & $\begin{array}{l}\text { Step 3 } \\
(\beta)\end{array}$ \\
\hline \multicolumn{4}{|l|}{ Block 1} \\
\hline Dummy_u1 & $-0.13 \dagger$ & $-0.06^{\star}$ & $-0.06^{*}$ \\
\hline Dummy_u2 & -0.01 & 0 & 0 \\
\hline Dummy_u3 & -0.03 & -0.02 & -0.02 \\
\hline Dummy_r1 & $-0.14 \dagger$ & $-0.12 \dagger$ & $-0.10 \dagger$ \\
\hline Dummy_r2 & $-0.12 \dagger$ & $-0.20 \dagger$ & $-0.17 \dagger$ \\
\hline Nightshift & $-0.11 \dagger$ & $-0.10 \dagger$ & $-0.10 \dagger$ \\
\hline $\begin{array}{l}\text { Looking after the } \\
\text { elderly }\end{array}$ & -0.03 & $-0.05^{\star}$ & $-0.05^{\star}$ \\
\hline Sleep disorders & $-0.22 \dagger$ & $-0.16 \dagger$ & $-0.13 \dagger$ \\
\hline Chronic disease & $-0.12 \dagger$ & $-0.10 \dagger$ & $-0.09 \dagger$ \\
\hline $\begin{array}{l}\text { Frequent overtime } \\
\text { work }\end{array}$ & $-0.19 \dagger$ & $-0.13 \dagger$ & $-0.13 \dagger$ \\
\hline
\end{tabular}

Block 2

NLS

$0.55+$

$0.39+$

Block 3

\begin{tabular}{lccc} 
Active coping & & & $0.22 \dagger$ \\
Passive coping & & & $-0.13 \dagger$ \\
$\mathrm{R} 2$ & 0.18 & 0.45 & 0.49 \\
$\Delta \mathrm{R} 2$ & 0.18 & 0.27 & 0.04 \\
\hline
\end{tabular}

Dummy_u1=medical ward versus surgical ward; dummy_ u2=medical ward versus gynaecology/pediatric ward; dummy_ u3=medical ward versus others. Dummy_r1=junior versus intermediate; dummy_r2=junior versus senior.

${ }^{*} \mathrm{P}<0.05$.

$\dagger P<0.01$ (two-tailed).

NLS, Nurse Leadership Scale; WRQoL-2, work-related Quality of Life Scale-2.

leadership was positively associated with QWL $(\mathrm{r}=0.58$, $\mathrm{p}<0.01)$. Active coping $(\mathrm{r}=0.50, \mathrm{p}<0.01)$ was positively related to $\mathrm{QWL}$, whereas passive coping $(\mathrm{r}=-0.32, \mathrm{p}<0.01)$ was negatively related to QWL. Furthermore, clinical leadership was positively related to active coping $(r=0.58$, $\mathrm{p}<0.01)$ and negatively related to passive coping $(\mathrm{r}=-0.28$, $\mathrm{p}<0.01)$.

\section{The results of the hierarchical multiple linear regression}

As shown in table 3, clinical leadership contributed to $27 \%$ and coping styles contributed to $4 \%$ of the variance in QWL, respectively. Clinical leadership was positively associated with $\mathrm{QWL}(\beta=0.55, \mathrm{p}<0.01)$. Active coping was positively associated with $\mathrm{QWL}(\beta=0.22, \mathrm{p}<0.01)$ whereas passive coping was negatively associated with QWL $(\beta=-0.13, p<0.01)$. After adding coping styles to the model in step 3 , the absolute value of regression coefficient of clinical leadership on QWL was reduced from 0.55 to 0.39 ; however, the effect of clinical leadership on QWL was still significant.
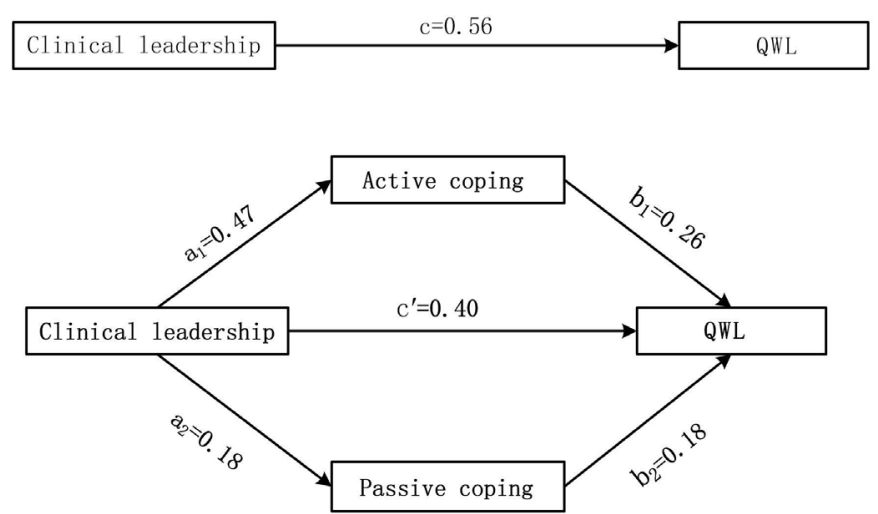

Figure 2 Model of the mediating role of active and passive coping between clinical leadership and QWL. c: total effect of clinical leadership on QWL; $a_{1}$ : clinical leadership was positively associated with active coping; $b_{1}$ : active coping was positively associated with QWL after controlling for clinical leadership being positively associated with active coping; $a_{2}$ : clinical leadership was negatively associated with passive coping; $b_{2}$ : passive coping was negatively associated with QWL after controlling for NLS being negatively associated with passive coping; c': direct effect of NLS on QWL after including active coping and passive coping as mediators. NLS, Nurse Leadership Scale; QWL, quality of work life.

The mediating role of coping style in the relationship between clinical leadership skills and QWL

Path coefficients are presented in figure 2. The total effect of clinical leadership on QWL (path c) was initially evaluated. Next, the indirect effects of clinical leadership on QWL via coping styles (active and passive coping) were observed (path $\mathrm{a} \times \mathrm{b}$ ). Finally, the direct effect of clinical leadership on QWL (path c') was still significant when coping styles (active and passive coping) were included in the model as a mediator; namely, the BCa $95 \%$ CIs did not include 0 . Therefore, it was concluded that active coping had a partial mediating effect on the relationship between clinical leadership and QWL (a×b (BCa $95 \% \mathrm{CI})=0.12(0.09$ to 0.16$)$ ) and passive coping had a partial mediating effect on the relationship between clinical leadership and QWL $(\mathrm{a} \times \mathrm{b}(\mathrm{BCa} 95 \% \mathrm{CI})=0.03(0.02$ to 0.05$)$ ). To understand the effect size of the mediating pathways, the proportion of the total effect of the independent variable on the dependent variable that was mediated by each coping style was calculated using the formula $(\mathrm{a} \times \mathrm{b}) / \mathrm{c}$. The proportion of mediation of active coping was $21.82 \%$ and of passive coping was $5.79 \%$.

\section{DISCUSSION}

The results of the mean overall QWL score $(3.50 \pm 0.60)$ were at the moderate level, consistent with results of relevant studies in both China and other countries. ${ }^{515}$ This could be due to a number of reasons. Currently, tertiary general hospitals have a large number of patients whose conditions are relatively serious and complicated. Moreover, there is a lack of sufficient nurses who can meet 
the high patient care needs, which often results in an excessive work overload (including prolonged working hours and frequent night shifts) from each nurse. In the current study, we found that the higher the frequency of night shifts and overtime work per week, the lower the nurses' QWL. Irregular life caused by nightshifts and the heavy and cumbersome tasks faced by nurses reduced their QWL. ${ }^{39} 40$ The current study also found that nurses with sleep disorders, chronic diseases and with elderly-caretaking responsibilities tended to have a lower QWL. Akter et $a t^{41}$ demonstrated that poor health status, including suffering from both physical pain and psychological stress, were barriers to nurses' lives and work. Indeed, nurses are often obstructed from getting good rest due to sleep disorders. They tend to worry about their health conditions and have to take care of their relatives which, over time, will lead to nurse fatigue. Fatigue, feelings of weakness, and weariness of mind may interfere with one's ability to remain focused at work and be successful in their role as a caregiver. ${ }^{42}$ Because of these stressors, nurses were unable to concentrate on their work and had a lower QWL.

The associations among clinical leadership, coping style and QWL of nurses were explored in the current study. Consistent with previous studies, clinical leadership was positively associated with QWL among nurses. Boamah ${ }^{43}$ reported that nurses' clinical leadership behaviours at the bedside had a direct positive effect on their perceptions of patient care quality and job satisfaction, and that job satisfaction was related to lower adverse events. In a qualitative study, Ennis $e t a t^{20}$ demonstrated that clinical leadership had a positive impact on nurses' professional growth and development through the leaders' rolemodelling behaviours, willingness to share knowledge and approachability. Collectively, these studies suggest that clinical leadership contributes to creating a positive work environment that facilitates learning and supports professional development. Clinical leadership is an ability that nurses should have and can promote both professional development as well as an independent implementation of work procedures. ${ }^{21}{ }^{44}$ Nurses are not only the caregivers of patients, but are also the leaders of patients. Leadership is exerted by nurses to allow patients to follow their guidance for promoting the recovery of diseases. Effective clinical leadership can influence patients' outcomes, enhance job satisfaction and improve nurses' QWL. ${ }^{45}$ Therefore, it is suggested that effective interventions to promote the level of clinical leadership for nurses to be developed and implemented.

Nurses are under high stress at work due to high workloads. Previous studies have examined the role of coping style in influencing QWL. ${ }^{46-48}$ The data from the current study are consistent with previous studies in that active coping was positively associated with QWL, whereas passive coping was negatively associated with QWL among nurses. Nurses often experience high levels of job pressures and heavy workloads. Motamed-Jahromi $e t a t^{49}$ described that optimistic coping style, such as a positive thinking approach, helps to enable nurses to cope with daily stress. Active coping styles encourage individuals to pursue their goals and realise their full potential. Indeed, an individual with active coping strategies can evaluate stressful conditions and successfully deal with difficulties in their life. This may be a reason why a nurse with an effective use of active coping strategies has a high QWL. Evidence suggests that passive coping styles can alleviate symptoms for a short period of time; however, they can be detrimental in the long run. ${ }^{50}$ To avoid the distress of work, for example, they chose to forget it for a while or adopt unhealthy behaviours such as smoking and drinking. However, these behaviours do not eliminate the stressor; it still affects them and reduces their QWL.

Coping style was found to partially mediate the relationship between clinical leadership and QWL among nurses. Simply put, the current study found that clinical leadership both directly affected and indirectly affected, via coping styles, QWL. Coping is described as a psychological response exhibited by individuals when managing distress, such as job stress. ${ }^{51}$ Individuals can actively and consciously select and engage in certain coping behaviours. ${ }^{24}$ Clinical leadership is regarded as having competencies for improving patient outcomes through an integration of knowledge, skills, abilities and judgement. Nurses with a high level of clinical leadership were most likely to adopt positive coping strategies such as focusing on deeply held values, beliefs and goals, which further lead to higher levels of QWL. ${ }^{53}$ Passive coping styles (as a risk factor) reduce the positive impact of clinical leadership (as a positive factor) on QWL. These findings suggest that QWL of nurses could be promoted by enhancing the level of clinical leadership and/or developing active coping strategies. Mianda and Voce $^{54}$ demonstrated that interventions for clinical leadership development involved the development of clinical skills, leadership competencies, teamwork, as well as the environment of care and patient care. Therefore, clinical leadership development and coping skills training are suggested to be included in the programme of improving nurses' QWL.

Several limitations of the current study should be mentioned. First, this study focused only on the associations of clinical leadership and coping style with QWL. Other factors such as personality of nurses and work environment, which are also important factors to consider, were not included. ${ }^{16}{ }^{41}$ Second, clinical leadership was obtained from self-reports. Respondents may have underestimated or overestimated the level of their own clinical leadership. The level of clinical leadership can also be evaluated by others, such as managers or patients. We recognised that this self-report bias might have affected the results. Third, the participants were selected and came from one provincial tertiary hospital, which may limit the generalisability of the findings. Tertiary hospitals in different geographical locations and level of economic development may take on different tasks and workload, so a multistage and stratified sampling design 
was employed to ensure that study data were representative. Finally, $96.9 \%$ of the respondents are women in this study. It represents the gender composition of nurses in tertiary-level hospitals in China. ${ }^{1155}$ However, due to limited sample size of male nurses in this study, future studies with a more robust sample size of male nurses, for example, covering different geographical regions, may further enhance the power to determine the impact of gender on QWL and other variables.

\section{CONCLUSIONS}

After adjusting for demographic characteristics, clinical leadership was positively associated with nurses' QWL. Clinical leadership explained $27 \%$ of the variance in their QWL. Coping style was found to partially mediate the relationship between clinical leadership and nurses' QWL. Nurses with higher levels of clinical leadership may use active coping styles, which in turn could lead to higher levels of QWL. This study provided further evidence for the Lazarus and Folkman's transitional model to the field of nursing management. Therefore, effective strategies should be implemented to improve clinical leadership and coping styles among nurses and enhance QWL among nurses. It is essential that nurse managers organise educational and training programmes to develop leadership skills, provide nurses with relative coping knowledge and techniques, and to improve their clinical leadership and coping ability. Besides that, leadership and coping strategies development programmes should be implemented at medical schools to improve clinical leadership and coping skills for nursing students.

Acknowledgements We would like to give our heartfelt thanks to all of the nurses who participated in the current study. Without them, this study would not have been possible.

Contributors $\mathrm{HL}$ and $\mathrm{XL}$ designed the study. $\mathrm{HL}, \mathrm{HC}, \mathrm{DZ}$ and $\mathrm{YS}$ collected the data. $\mathrm{HC}$ and ZT analysed the data. HL and XL drafted the manuscript. HC, ZT, DZ and YS revised the manuscript. All authors read and approved the final manuscript.

Funding This study was supported by grant funding from the School of Nursing of China Medical University, grant no. 2017HL-25.

Competing interests None declared.

Patient and public involvement Patients and/or the public were not involved in the design, or conduct, or reporting, or dissemination plans of this research.

Patient consent for publication Not required.

Ethics approval The Ethics Committee on Human Experimentation of the First Affiliated Hospital of China Medical University reviewed and provided approval for this study and study procedures were in accordance with the ethical standards (Reg. No. 2019-221-2). Written informed consent was obtained prior to the survey; all personal information of participants remained confidential.

Provenance and peer review Not commissioned; externally peer reviewed.

Data availability statement Data are available upon reasonable request. Original data are available on request. Please contact the corresponding author for further information.

Open access This is an open access article distributed in accordance with the Creative Commons Attribution Non Commercial (CC BY-NC 4.0) license, which permits others to distribute, remix, adapt, build upon this work non-commercially, and license their derivative works on different terms, provided the original work is properly cited, appropriate credit is given, any changes made indicated, and the use is non-commercial. See: http://creativecommons.org/licenses/by-nc/4.0/.
ORCID iD

Xiaofei Li http://orcid.org/0000-0001-8395-9775

\section{REFERENCES}

1 Daubermann D, Tonete PV. Quality of work life of nurses in primary health care. Acta Paul Enferm 2012;25:277-83.

2 Leitão J, Pereira D, Gonçalves Ângela. Quality of work life and organizational performance: workers' feelings of contributing, or not, to the organization's productivity. Int $J$ Environ Res Public Health 2019;16:3803.

3 Sattar Set al. Relation of job related factors with different dimensions of quality of work life. WJPH 2018;3:16-22.

4 Melnyk BM, Gallagher-Ford L, Zellefrow C, et al. The first U.S. study on nurses' evidence-based practice competencies indicates major deficits that threaten healthcare quality, safety, and patient outcomes. Worldviews Evid Based Nurs 2018;15:16-25.

5 Moradi T, Maghaminejad F, Azizi-Fini I. Quality of working life of nurses and its related factors. Nurs Midwifery Stud 2014;3:e19450.

6 Aiken LH, Sloane D, Griffiths P, et al. Nursing skill mix in European hospitals: cross-sectional study of the association with mortality, patient ratings, and quality of care. BMJ Qual Saf 2017;26:559-68.

7 Ammouri AA, Tailakh AK, Muliira JK, et al. Patient safety culture among nurses. Int Nurs Rev 2015;62:102-10.

8 Ruppel H, Funk M. Nurse-technology interactions and patient safety. Crit Care Nurs Clin North Am 2018;30:203-13.

9 Schulz M, Damkröger A, Voltmer E, et al. Work-related behaviour and experience pattern in nurses: impact on physical and mental health. J Psychiatr Ment Health Nurs 2011;18:411-7.

10 Siebenhüner K, Battegay $\mathrm{E}$, Hämmig O. Temporal work stressors and satisfaction with work, life and health among health professionals in Switzerland. Swiss Med Wkly 2020;150:w20175.

11 Liu W, Zhao S, Shi L, et al. Workplace violence, job satisfaction, burnout, perceived organisational support and their effects on turnover intention among Chinese nurses in tertiary hospitals: a cross-sectional study. BMJ Open 2018;8:e019525.

12 Wagner C. Moral distress as a contributor to nurse burnout. Am J Nurs 2015;115:11.

13 Almalki MJ, FitzGerald G, Clark M. The relationship between quality of work life and turnover intention of primary health care nurses in Saudi Arabia. BMC Health Serv Res 2012;12:314.

14 Lee Y-W, Dai Y-T, Chang MY, et al. Quality of work life, nurses' intention to leave the profession, and nurses leaving the profession: a one-year prospective survey. J Nurs Scholarsh 2017;49:438-44.

15 Wang L, Wang X, Liu S, et al. Analysis and strategy research on quality of nursing work life. Medicine 2020;99:e19172.

16 Viselita F, Handiyani H, Pujasari H. Quality level of nursing work life and improvement interventions: systematic review. Enferm Clin 2019;29:223-8.

17 Dansereau F, Seitz SR, Chiu C-Y, et al. What makes leadership, leadership? Using self-expansion theory to integrate traditional and contemporary approaches. Leadersh Q 2013;24:798-821.

18 Grindel CG. Clinical leadership: a call to action. Medsurg Nurs 2016;25:9-16.

19 Supamanee T, Krairiksh M, Singhakhumfu L, et al. Preliminary clinical nursing leadership competency model: a qualitative study from Thailand. Nurs Health Sci 2011;13:433-9.

20 Ennis G, Happell B, Reid-Searl K. Enabling professional development in mental health nursing: the role of clinical leadership. J Psychiatr Ment Health Nurs 2015;22:616-22.

21 Rosengren K, Athlin E, Segesten K. Presence and availability: staff conceptions of nursing leadership on an intensive care unit. J Nurs Manag 2007;15:522-9.

22 Munir F, Nielsen K, Garde AH, et al. Mediating the effects of worklife conflict between transformational leadership and health-care workers' job satisfaction and psychological wellbeing. J Nurs Manag 2012;20:512-21.

23 Zhou H, Peng J, Wang D, et al. Mediating effect of coping styles on the association between psychological capital and psychological distress among Chinese nurses: a cross-sectional study. J Psychiatr Ment Health Nurs 2017;24:114-22.

24 Lazarus RS, Folkman S. The concept of coping. Stress Appraisal \& Coping 1996;12:385-95.

25 Portero de la Cruz S, Cebrino J, Herruzo J, et al. A multicenter study into burnout, perceived stress, job satisfaction, coping strategies, 
and general health among emergency department nursing staff. $J$ Clin Med 2020;9:1007.

$26 \mathrm{Li} \mathrm{L}, \mathrm{Ai} \mathrm{H}, \mathrm{Gao}$ L, et al. Moderating effects of coping on work stress and job performance for nurses in tertiary hospitals: a cross-sectional survey in China. BMC Health Serv Res 2017;17:401.

27 Rotman M, Andela CD, Majoor BCJ, et al. Passive coping strategies are associated with more impairment in quality of life in patients with fibrous dysplasia. Calcif Tissue Int 2018;103:469-75.

28 Lazarus RS, Folkman S. Stress, appraisal, and coping. New York: Springer, 1984.

29 Pepin J, Dubois S, Girard F, et al. A cognitive learning model of clinical nursing leadership. Nurse Educ Today 2011;31:268-73.

30 Pishgooie AH, Atashzadeh-Shoorideh F, Falcó-Pegueroles A, et al. Correlation between nursing managers' leadership styles and nurses' job stress and anticipated turnover. J Nurs Manag 2019;27:527-34.

31 García-Sierra R, Fernández-Castro J. Relationships between leadership, structural empowerment, and engagement in nurses. $J$ Adv Nurs 2018;74:2809-19.

32 Boamah SA, Spence Laschinger HK, Wong C, et al. Effect of transformational leadership on job satisfaction and patient safety outcomes. Nurs Outlook 2018;66:180-9.

33 Saleh U, O'Connor T, Al-Subhi H, et al. The impact of nurse managers' leadership styles on ward staff. Br J Nurs 2018;27:197-203.

34 Shao Y, Liao SL, Zhong HQ. Work-related quality of life scale among Chinese nurses: evaluation of the reliability and validity. J Nurs Sci 2014;29:1-3.

35 Jia JF. Research on nurse leadership and it's influencing factors: taking tertiary general hospital in certain district as an example. Hangzhou Normal University, 2013.

36 Dai YY. Correlation between leadership and personality among clinical nurses. J Nurs Admin 2016;16:83-4.

37 Xie YN. The initial exploration of reliability and validity of simplified coping styles questionnaire. Chinese J Clin Psychol 1998;6:114-5.

38 Preacher KJ, Hayes AF. Asymptotic and resampling strategies for assessing and comparing indirect effects in multiple mediator models. Behav Res Methods 2008;40:879-91.

39 Rahnavard F, Sadati AK, Hemmati S, et al. The impact of environmental and demographic factors on nursing job satisfaction. Electron Physician 2018;10:6712-7.

40 Dall'Ora C, Griffiths P, Ball J, et al. Association of $12 \mathrm{H}$ shifts and nurses' job satisfaction, burnout and intention to leave: findings from a cross-sectional study of 12 European countries. BMJ Open 2015;5:e008331.

41 Akter N, Akter MK, Turale S. Barriers to quality of work life among Bangladeshi nurses: a qualitative study. Int Nurs Rev 2019;66:396-403.

42 Bolandianbafghi S, Salimi T, Rassouli M, et al. Correlation between medication errors with job satisfaction and fatigue of nurses. Electron Physician 2017;9:5142-8.

43 Boamah SA. Emergence of informal clinical leadership as a catalyst for improving patient care quality and job satisfaction. J Adv Nurs 2019;75:1000-9.

44 Fischer SA. Transformational leadership in nursing: a concept analysis. J Adv Nurs 2016;72:2644-53.

45 Al-Dossary RN, Kitsantas P, Maddox PJ. Residency programs and clinical leadership skills among new Saudi graduate nurses. J Prof Nurs 2016;32:152-8.

46 SY W, HY L, Yang SJ. The mediating and moderating role of personal strain and coping resource in the relationship between work stressor and quality of life among Chinese nurses. Int Arch Occup Environ Health 2012;85:35-43.

47 Makabe S, Kowitlawakul Y, Nurumal MS, et al. Investigation of the key determinants of Asian nurses' quality of life. Ind Health 2018;56:212-9.

48 Cruz JP, Cabrera DNC, Hufana OD, et al. Optimism, proactive coping and quality of life among nurses: a cross-sectional study. J Clin Nurs 2018;27:2098-108.

49 Motamed-Jahromi M, Fereidouni Z, Dehghan A. Effectiveness of positive thinking training program on nurses' quality of work life through smartphone applications. Int Sch Res Notices 2017:4965816.

50 Wu C, Wang K, Sun T, et al. Predicting help-seeking intention of women with urinary incontinence in Jinan, China: a theory of planned behaviour model. J Clin Nurs 2015;24:457-64.

51 Lazarus RS, Folkman S, Lazarus R. Psychological stress and the coping process. Science 1966;156.

52 Folkman S, Moskowitz JT. Positive affect and the other side of coping. Am Psychol 2000;55:647-54.

53 Monzani D, Steca P, Greco A, et al. The situational version of the brief cope: dimensionality and relationships with goal-related variables. Eur J Psychol 2015;11:295-310.

54 Mianda S, Voce A. Developing and evaluating clinical leadership interventions for frontline healthcare providers: a review of the literature. BMC Health Serv Res 2018;18:747.

55 Zhang W, Miao R, Tang J. Burnout in nurses working in China: a national questionnaire survey. Int J Nurs Pract 2020:e12908. 